\title{
A Note on Non-linear Profit-Maximization Entropic Order Quantity (EnOQ) Model for Deteriorating Items with Stock Dependent Demand Rate
}

\author{
Monalisha Pattnaik \\ Deptartment of Business Administration, Utkal University, Bhubaneswar-751004, India \\ Email: monalisha1977@gmail.com
}

\begin{abstract}
A new type of non-linear profit maximization replenishment policy is suggested in an entropy order quantity model for deteriorating items with stock dependent demand rate. This model represents an appropriate combination of two component demand with entropy cost, particularly over a finite time horizon. Its main aim lies in the need for an entropic cost of the cycle time is a key feature of specific perishable products like fruits, vegetables, food stuffs, fishes etc. To handle this multiplicity of objectives in a pragmatic approach, entropic ordering quantity model with two component demand of perishable items to optimize its payoff is proposed. Two nonlinear profit-maximization models are formulated by considering the effects of entropy cost and without entropy cost. Finally to clearly illustrate the non-linear profit maximization EnOQ model a numerical example and the sensitivity analysis are also conducted in the optimal solutions when different parameters are changed. It is considered that if the entropy is allowed in the model, the profit is approximately less in comparison to the non entropic model but the order quantity is more in EnOQ model. In addition, a comparative analysis between the profit-maximization models is conducted.
\end{abstract}

Keywords: stock dependent demand, deterioration, entropy, profit maximization, inventory

\section{INTRODUCTION}

This paper establishes and analyzes a non-linear inventory model under profit-maximization which extends the classical economic order quantity (EOQ) model. The extensions to the EOQ model by this model are introducing the entropy cost. In deriving and analyzing the optimal solutions of non-linear problem, LINGO software is used.

The predominant criterion in traditional inventory models is minimization of long-run average cost per unit time. The costs considered are usually fixed and variable ordering cost, holding cost, disposal cost. Costs associated with disorder in a system tied up in inventory are accounted for by including an entropy cost in the total costs. Entropy is frequently defined as the amount of disorder in a system. Jaber et al. (2008) proposed an analogy between the behaviour of production system and the behaviour of physical system. This paper introduced the concept of entropy cost to account for hidden cost such as the additional managerial cost that is needed to control the improvement process.

Product perishability is an important aspect of inventory control. Deterioration in general, may be considered as the result of various effects on stock, some of which are damage, decay, decreasing usefulness and many more. While kept in store fruits, vegetables, food stuffs etc. suffer from depletion by decent spoilage. Decaying products are of two types. Product which deteriorate from the very beginning and the products which start to deteriorate after a certain time. Lot of articles are available in inventory literature considering deterioration. Interested readers may consult the survey paper of Tripathy and Pattnaik (2008) investigate an entropic order quantity model for perishable items with pre and post deterioration discounts under two component demand in fuzzy decision space. Pattnaik (2010) discusses an entropic order quantity model for perishable items with constant demand where instant post deterioration discount is allowed to obtain maximum profit. Panda et al. (2009) derive an EOQ model for perishable items under two component demand where pre and post deterioration discounts are allowed in crisp decision space. Weatherford and Bodily (1992), Goyal and Giri (2001) and Raafat (1991) survey for perishable items to optimize the model.

The constant demand model appears to have received considerably less attention in the inventory literature than the two component demand function model. In last two decades the variability of inventory level dependent demand rate on the analysis of inventory system was described by researchers like Pal et al. (1993), Goswami and Choudhury (1995) and Silver and Peterson (1985). They described the demand rate as the power function of on hand inventory. There is a vast literature on stock development inventory and its outline can be found in the review article by Urban (2005) where he unified two types of inventory level dependent demand by considering a periodic review model. Researchers such as Pattnaik (2011), Chung et al. (2007), Goswami and Choudhury (1995), Goyal and Giri (2001), Pal et al. (1993), Raafat (1991), Wee and Law (2001) and Skouri et al. (2007) discussed the EOQ model assuming time value of money, demand rate, deterioration rate, shortages and so on a constant or probabilistic number or an exponential function. This paper considers two component demand function initially depending on inventory up to deterioration and then it becomes a constant function till stock is zero for 
Table 1. Major Characteristics of Inventory Models on Selected Researches

\begin{tabular}{|c|c|c|c|c|c|c|c|}
\hline $\begin{array}{c}\text { Author(s) and } \\
\text { published Year }\end{array}$ & $\begin{array}{c}\text { Structure of } \\
\text { the Model }\end{array}$ & Deterioration & $\begin{array}{c}\text { Inventory } \\
\text { Model } \\
\text { Based on }\end{array}$ & $\begin{array}{c}\text { Type of } \\
\text { model }\end{array}$ & $\begin{array}{c}\text { Discount } \\
\text { allowed }\end{array}$ & Demand & $\begin{array}{c}\text { Back- } \\
\text { logging } \\
\text { allowed }\end{array}$ \\
\hline $\begin{array}{c}\text { Panda et al. } \\
\text { (2009) }\end{array}$ & Crisp & $\begin{array}{c}\text { Yes } \\
\text { (Heaviside) }\end{array}$ & EOQ & Profit & Yes & $\begin{array}{c}\text { Stock } \\
\text { dependent }\end{array}$ & No \\
\hline Jaber et al. (2008) & Crisp & $\begin{array}{c}\text { Yes (on hand } \\
\text { inventory) }\end{array}$ & EnOQ & Profit & No & $\begin{array}{c}\text { Unit selling } \\
\text { price }\end{array}$ & No \\
\hline $\begin{array}{c}\text { Chung et al. } \\
(2007)\end{array}$ & Crisp & $\begin{array}{c}\text { Yes } \\
\text { (exponential) }\end{array}$ & EOQ & Profit & No & $\begin{array}{c}\text { Selling } \\
\text { price }\end{array}$ & $\begin{array}{c}\text { Yes } \\
\text { (partial) }\end{array}$ \\
\hline $\begin{array}{c}\text { Skouri et al. } \\
(2007)\end{array}$ & Crisp & $\begin{array}{c}\text { Yes } \\
\text { (Weibull) }\end{array}$ & EOQ & Cost & No & Ramp & $\begin{array}{c}\text { Yes } \\
\text { (partial) }\end{array}$ \\
\hline $\begin{array}{c}\text { Tripathy et al. } \\
\text { (2008) }\end{array}$ & Fuzzy & $\begin{array}{c}\text { Yes } \\
\text { (Heaviside) }\end{array}$ & EnOQ & Profit & Yes & $\begin{array}{c}\text { Stock } \\
\text { dependent }\end{array}$ & No \\
\hline $\begin{array}{c}\text { Pattnaik (2010) } \\
\text { (constant) }\end{array}$ & Crisp & EnOQ & Profit & Yes & Constant & No \\
\hline $\begin{array}{c}\text { Yes } \\
\text { Pattnaik (2011) }\end{array}$ & Crisp & EnOQ & Profit & Yes & $\begin{array}{c}\text { Stock } \\
\text { dependent }\end{array}$ & No \\
\hline $\begin{array}{c}\text { Present paper } \\
(2011)\end{array}$ & Crisp & $\begin{array}{c}\text { Yes } \\
\text { (Heaviside) }\end{array}$ & EnOQ & Profit & No & $\begin{array}{c}\text { Stock } \\
\text { dependent }\end{array}$ & No \\
\hline
\end{tabular}

the perishable products like fruits, vegetables, food stuffs, fishes etc.

The purpose of this paper is to investigate the effect of the approximation made by using the average payoff when determining the optimal values of the policy variables. This paper focuses exclusively on the cost of entropy with two component demand. A policy iteration algorithm is designed for non-linear problem with the help of Deb (2000) and optimum solution is obtained through the LINGO software. Numerical experiments are carried out to analyse the magnitude of the approximation error.

The major assumptions used in the above research articles are summarised in Table 1. The remainder of this paper is organised as follows. In section 2 assumptions and notations are provided for the development of the model. Section 3 describes the model formulation with other case. In section 4, an illustrative numerical experiment is given to illustrate the procedure of solving the model. In section 5 the paper describes the comparative evaluation and section 6 studies the sensitivity analysis of the present model. Section 7 provides the critical discussion of the present paper relating with the papers. Finally in section 8 summary and concluding remarks are provided with some suggestions for future research.

\section{NOTATIONS AND ASSUMPTIONS}

\subsection{Notations}

$\mathrm{C}_{0} \quad$ : set up cost

c : per unit purchase cost of the product

$\mathrm{s} \quad$ : constant selling price of the product per unit $(s>c)$

h $\quad$ : holding cost per unit per unit time

$\mathrm{Q}_{\mathrm{i}} \quad:(\mathrm{i}=1,2)$ order level for crisp entropic order quantity (CEnOQ) and crisp economic order quantity (CEOQ) models respectively.

$\mathrm{T}_{\mathrm{i}} \quad:(\mathrm{i}=1,2)$ cycle lengths for above all the two respective cases

\subsection{Assumptions}

1. Replenishment rate is infinite

2. The deterioration rate $\tilde{\theta}=\theta H(t-\tau),(0<\theta \leq 1)$ constant. Where $t$ is the time measured from the instant arrivals of a fresh replenishment indicating that the deterioration of the items begins after a time $\tau$ from the instant of the arrival in stock. $H(t-\tau)$ is the wellknown Heaviside's function. $\mathrm{H}(\mathrm{t}-\tau)=\left\{\begin{array}{l}1, t \geq \tau \\ 0, \text { otherwise }\end{array}\right.$

3. Demand depends on the on hand inventory up to time $\tau$ from time of fresh replenishment beyond which it is constant and defined as follows.

$R(I(t))=\left\{\begin{array}{l}a+b I(t), \quad t<\tau \\ a, t \geq \tau\end{array}\right.$

Where $a>0$ is the initial demand rate independent of stock level and condition of inventory. $b>0$ is the stock sensitive demand parameter $I(t)$ is the instantaneous inventory level at time $t$.

4. Entropy generation rate must satisfy $S=\frac{d \sigma(t)}{d t}$ where, $\sigma(t)$ is the total entropy generated by time $t$ and $S$ is the rate at which entropy is generated. The entropy cost is computed by dividing the total commodity flow in a cycle of duration $T_{1}$. The total entropy generated over time $\mathrm{T}_{1}$ as $\sigma\left(T_{1}\right)=\int_{0}^{T_{1}} S d t, S=\frac{R(I(t))}{s}$

Entropy cost per cycle is

EC $\left(T_{i}\right)=(E C)_{\text {Without deterioration }}+(E C)$ With deterioration $=\frac{D(\tau)}{\sigma(\tau)}+\frac{Q_{1} \text { With deterioration }}{\sigma\left(T_{1}\right)} E C$ is measured in an appropriate price unit with no deterioration and with deterioration respectively. 


\section{MATHEMATICAL MODEL}

At the beginning of the replenishment cycle the inventory level raises to $Q_{1}$. As time progresses it decreases due to instantaneous stock dependent demand up to the time $\tau$. After $\tau$ deterioration starts and the inventory level decreases for deterioration and constant demand. Ultimately inventory reaches zero level at $T_{l}$. Then the behaviour of inventory level is governed by the following system of linear differential equations.

$$
\begin{aligned}
D(I(t)) / d & =-a-b I(t) & & 0 \leq t \leq \tau \\
& =-[a+\theta I(t)] & & \tau \leq t \leq T_{1}
\end{aligned}
$$

With the initial boundary condition

$$
\begin{aligned}
& I(0)=Q_{l}, 0 \leq t \leq \tau \\
& I\left(T_{1}\right)=0, \tau \leq t \leq T_{1}
\end{aligned}
$$

Solving the equations,

$$
\begin{aligned}
I(t) & =\frac{a}{b}\left[e^{-b t}-1\right]+\left(Q_{1} \times e^{-b t}\right), 0 \leq t \leq \tau \\
& =\frac{a}{\theta}\left[e^{\theta\left(T_{1}-t\right)}-1\right], \tau \leq t \leq T_{1}
\end{aligned}
$$

Now, at the point $\mathrm{t}=\tau$ we have from equation (2) and (3).

$$
Q_{1}=\left[\frac{a}{\theta}\left(e^{\theta\left(T_{1}-\tau\right)}-1\right)+\frac{a}{b}\right] \times e^{b \tau}-\frac{a}{b}
$$

Holding cost of inventory in the cycle is,

$$
H C=h \int_{o}^{\tau} I(t) d t+h \int_{\tau}^{T_{1}} I(t) d t
$$

Purchase cost in the cycle is given by $P C=c Q_{l}$. Entropy cost in the cycle is

$$
\begin{aligned}
E C & =(E C)_{\text {without deterioration }}+(E C)_{\text {with deterioration }} . \\
& =\frac{D(\tau)}{\sigma(\tau)}+\frac{Q_{1} \text { with Deterioration }}{\sigma\left(T_{1}\right)} .
\end{aligned}
$$

Where

$$
\begin{aligned}
& D(\tau)=\int_{0}^{\tau} R(I(t)) d t, \\
& \sigma(\tau)=\int_{0}^{\tau} S d t=\int_{0}^{\tau} \frac{R(I(t))}{s} d t=\frac{1}{s} D(\tau), \\
& \sigma\left(T_{1}\right)=\int_{\tau}^{T_{1}} \frac{R(I(t))}{s} d t=\int_{\tau}^{T_{1}} \frac{a}{s} d t=\frac{a}{s}\left(T_{1}-\tau\right), \\
& E C=s+\frac{s Q_{1}}{a\left(T_{1}-\tau\right)}
\end{aligned}
$$

Total sales revenue in the order cycle can be found as $S R=s\left[\int_{0}^{\tau}[a+b I(t)] d t+\int_{\tau}^{T_{1}} a d t\right]$

Thus total profit per unit time of the system is $\pi_{1}\left(T_{1}\right)=\frac{1}{T_{1}}[S R-P C-H C-E C-O C]$

On integration and simplification of the relevant costs, the total profit per unit time becomes

$\pi_{1}=\frac{1}{T_{1}}\left[\begin{array}{l}s a \tau+s a\left(T_{1}-\tau\right)+(s b-h)\left(-\frac{a \tau}{b}+\left(Q_{1}+\frac{a}{b}\right)\left(\frac{1-e^{-b \tau}}{b}\right)\right)-\frac{h a}{\theta}\left(\frac{e^{\theta\left(T_{1}-\tau\right)}-1}{\theta}-\left(T_{1}-\tau\right)\right) \\ -s-\frac{s Q_{1}}{a\left(T_{1}-\tau\right)}-c Q_{1}-C_{0}\end{array}\right]$

Since, no discount is provided on the unit selling price of the product in CEnOQ model, no constraints will be imposed on equation (5). The only constraint is the nonnegative restriction for $T_{l}$. Hence,

Maximize $\pi_{1}\left(T_{1}\right)$

$\forall T_{1} \geq 0$

\section{Case-1 Profit Maximization for CEOQ Model}

In this case the entropy cost is ignored, so the order level and total profit per unit time is obtained from (4) and (5) by substituting $\mathrm{T}_{1}=\mathrm{T}_{2}$ and $\mathrm{EC}=0$.

$$
\begin{aligned}
& Q_{2}=\left[\frac{a}{\theta}\left(e^{\theta\left(T_{2}-\tau\right)}-1\right)+\frac{a}{b}\right] e^{b \tau}-\frac{a}{b} \\
& \pi_{2}=\frac{1}{T_{2}}[S R-P C-H C-O C]
\end{aligned}
$$

$$
=\frac{1}{T_{2}}\left[\begin{array}{l}
\left.s a \tau+s a\left(T_{2}-\tau\right)+(s b-h)\left(-\frac{a \tau}{b}+\left(Q_{2}+\frac{a}{b}\right)\left(\frac{1-e^{-b \tau}}{b}\right)\right)\right) \\
-(h) \frac{a}{\theta}\left(\frac{e^{\theta\left(T_{2}-\tau\right)}-1}{\theta}-\left(T_{2}-\tau\right)\right)-c Q_{2}-C_{0}
\end{array}\right] \text { (8) }
$$

Since, no discount is provided on the unit selling price of the product in CEOQ model, no constraints will be imposed on equation (8). The only constraint is the nonnegative restriction for $T_{2}$. Hence,

Maximize $\pi_{2}\left(T_{2}\right)$

$\forall T_{2} \geq 0$ 


\section{NUMERICAL EXAMPLE}

The parameter values are $\mathrm{a}=80, \mathrm{~b}=0.3, \mathrm{~h}=0.6, \mathrm{~s}=10.0$, $\mathrm{C}_{0}=100.0, \mathrm{c}=4.0, \theta=0.03, \tau=1.2$ are listed in Table 2 .

After 47 and 45 iterations Table 2 reveals the optimal replenishment policy for instant deterioration order quantity model with entropy cost and without entropy cost respectively. In Table 3 the numerical results of different CEOQ and CEnOQ models are illustrated separately. For the entropic order quantity model profit per unit time is 515.9152 , the optimal order quantity and cycle lengths are 344.1667 and 3.131757 respectively. The results are quite justified and agree with the model analysis at last section.

The relative differences in Table 3 is marked approximate than the ones found in the previous experiments when the ordering policy is optimal. This indicates that there exists case in which the relative difference is non-negligible. Based on the results in Tables- 2 and 3, it is also noted that the relative difference can be high when the ordering policy is optimal in the entropy order quantity model.

\section{COMPARATIVE EVALUATION}

Table 2 shows that the entropy cost, 32.212812 in CEnOQ deteriorated model is provided on unit selling price to lose $2.06 \%$ less profit than that with CEOQ deteriorated model. From Table 3 it indicates that the entropy cost and price discount on selling price are provided on the deterioration models to earn $0.54 \%, 29.84 \%$ and $29.97 \%$ more profits for CEnOQ without discount and with discount models respectively than that with present CEnOQ model. Similarly it shows that this no discounted deterioration model to lose $1.66 \%, 12.86 \%$ and $17.54 \%$ less profits for CEOQ with discount free model, CEnOQ and CEOQ with discount models respectively than that with present CEnOQ model. This paper investigates a computing schema for the EnOQ and EOQ in crisp sense. From Table 3 it shows that the EnOQ and EOQ results are very approximate, i.e. it permits better use of EnOQ as compared to crisp space arising with the EOQ model and other related inventory models. Tripathy and Pattnaik (2008) investigate an entropic order quantity model for perishable items under two component demand where pre and post deterioration discounts are allowed in fuzzy decision space. Pattnaik (2010) derives an entropic order quantity model for perishable items under instant deterioration post discounts are allowed in crisp decision space. It indicates the consistency of the crisp space of EnOQ from EOQ models.

Table 2. The Numerical Results of the Instant Deterioration CEnOQ and CEOQ Models (i=1,2)

\begin{tabular}{|c|c|c|c|c|c|}
\hline Model & $\begin{array}{c}\text { Local optimal } \\
\text { solution found at } \\
\text { iteration }\end{array}$ & $\mathrm{T}_{\mathrm{i}}$ & $\mathrm{Q}_{\mathrm{i}}$ & $\mathrm{EC}$ & $\pi_{\mathrm{i}}$ \\
\hline CEnOQ & 47 & 3.131757 & 344.1667 & 32.212812 & 515.9152 \\
\hline CEOQ & 45 & 2.8799 & 313.0764 & - & 526.7771 \\
\hline
\end{tabular}

Table 3. Comparison of Results and Relative Errors (RE) of Instant Deterioration EnOQ Model with different Models $(i=1,2,3,4,5,6,7,8)$

\begin{tabular}{|c|c|c|c|c|c|c|}
\hline Model & $\begin{array}{c}\text { Local optimal } \\
\text { solution found at } \\
\text { iteration }\end{array}$ & Discount & $\mathrm{T}_{\mathrm{i}}$ & $\mathrm{Q}_{\mathrm{i}}$ & $\mathrm{EC}$ & $\pi_{\mathrm{i}}$ \\
\hline CEOQ & 45 & - & 2.8799 & 313.0764 & - & 526.7771 \\
\hline$\%$ Change & 4.2553 & - & 8.1886 & 9.0335 & - & -2.0620 \\
\hline $\begin{array}{c}\text { CEnOQ Tripathy } \\
\text { et al. }(2008)\end{array}$ & - & - & 3.034417 & 331.7506 & - & 513.1098 \\
\hline$\%$ Change & - & - & 3.2631 & 3.6076 & - & 0.5438 \\
\hline $\begin{array}{c}\text { CEOQ Tripathy et } \\
\text { al. }(2008)\end{array}$ & 50 & - & 2.7822 & 301.3188 & - & 524.4967 \\
\hline$\%$ Change & -6.3830 & - & 11.3032 & 12.4498 & - & -1.6634 \\
\hline $\begin{array}{c}\text { CEnOQ Pattnaik } \\
(2011)\end{array}$ & 78 & 0.4138 & 2.8319 & 673.5408 & 61.5918 & 582.2379 \\
\hline$\%$ Change & -87.2340 & - & 18.0056 & -90.1865 & & -17.5358 \\
\hline $\begin{array}{c}\text { CEnOQ Pattnaik } \\
(2010)\end{array}$ & 141 & 0.0464 & 1.9176 & 173.6135 & 21.3170 & 362.0803 \\
\hline$\%$ Change & -200 & - & 38.8676 & 49.5554 & 33.8244 & 29.8352 \\
\hline $\begin{array}{c}\text { CEnOQ Pattnaik } \\
(2010) \\
\end{array}$ & 49 & - & 2.0009 & 164.9528 & 20.3051 & 361.2894 \\
\hline$\%$ Change & -4.2553 & - & 36.2121 & 52.0718 & 36.9657 & 29.9712 \\
\hline
\end{tabular}


Table 4: Sensitivity Analysis of Instant Deteriorated CEnOQ and CEOQ Models

\begin{tabular}{|c|c|c|c|c|c|c|c|c|}
\hline Model & Parameter & $\begin{array}{c}\% \\
\text { Change } \\
\end{array}$ & $\mathrm{T}_{\mathrm{i}}$ & $\%$ Change & $\mathrm{Q}_{\mathrm{i}}$ & $\%$ Change & $\pi_{\mathrm{i}}$ & $\%$ Change \\
\hline \multirow{6}{*}{ CEnOQ } & \multirow{2}{*}{ c } & +20 & 3.6747 & -17.150 & 410.0641 & -19.147 & 866.5516 & -67.964 \\
\hline & & +40 & 3.5000 & -11.580 & 388.5565 & -0.1290 & 777.5110 & -50.705 \\
\hline & \multirow{2}{*}{$\mathrm{a}$} & +20 & 5.0514 & -61.039 & 116.7253 & 66.0847 & 76.9651 & 85.0818 \\
\hline & & +40 & 3.9408 & -25.633 & 177.2217 & 48.5070 & 182.7003 & 64.5871 \\
\hline & \multirow{2}{*}{$\mathrm{C}_{0}$} & +20 & 2.6183 & 16.5284 & 281.6623 & 18.1611 & 541.4379 & -4.9471 \\
\hline & & +40 & 2.7254 & 13.1141 & 294.4872 & 14.4347 & 533.9518 & -3.4960 \\
\hline \multirow{6}{*}{ CEOQ } & \multirow{2}{*}{ c } & +20 & 1.2000 & 61.7439 & 403.8950 & -17.355 & 879.0136 & -70.380 \\
\hline & & +40 & 1.2000 & 61.7439 & 115.5402 & 66.4290 & 692.8813 & -34.301 \\
\hline & \multirow[b]{2}{*}{$\mathrm{a}$} & +20 & 1.2000 & 61.7439 & 23.10805 & 93.2858 & 25.6935 & 95.0198 \\
\hline & & +40 & 3.6832 & -17.421 & 164.4455 & 52.2192 & 192.4358 & 62.7001 \\
\hline & \multirow{2}{*}{$\mathrm{C}_{0}$} & +20 & 2.3289 & 25.7545 & 247.1813 & 28.1798 & 557.4856 & -8.0576 \\
\hline & & +40 & 2.4791 & 20.9661 & 265.0333 & 22.9928 & 549.1662 & -6.4451 \\
\hline
\end{tabular}

\section{SENSITIVITY ANALYSIS}

This paper has examined the sensitiveness of the decision variables, $T_{i}, Q_{i}$ and $\pi_{i}(i=1,2)$ for each set of the parameters $\left(\mathrm{c}, \mathrm{a}, \mathrm{C}_{0}\right)$ respectively shown in Table 4 . Table 4 shows the relative changes of the cycle lengths, $\mathrm{T}_{1}$ and $\mathrm{T}_{2}$, the order quantities, $\mathrm{Q}_{1}$ and $\mathrm{Q}_{2}$ and the total profits per unit time, $\pi_{1}$ and $\pi_{2}$, respectively when each of the parameters is being changed from $+20 \%$ to $+40 \%$.

From Table 4, it can be seen that in both the models the optimum cycle lengths $T_{1}$ and $T_{2}$ are less sensitive with respect to the parameters $\mathrm{c}$, a and $\mathrm{C}_{0}$ respectively. It also shows that the optimum order quantity, $\mathrm{Q}_{1}$ and $\mathrm{Q}_{2}$ are moderately sensitive with respect to the change in parameters $\mathrm{c}$, a and $\mathrm{C}_{0}$. On the other hand, it is observed that the optimal total profit per unit time, $\pi_{1}$ and $\pi_{2}$, are highly sensitive with respect to the parameters $\mathrm{c}$ and $\mathrm{a}$; and are less sensitive for the change in the parameter $\mathrm{C}_{0}$ respectively. Since the entropy cost is allowed and the discount factor is not present in the model to control over the system, the maximum profit is increased then decreased when the purchase cost is increased.

\section{CRITICAL DISCUSSION}

The mathematical model is developed allowing entropy cost in crisp environment. The numerical example is presented to justify the claim of model fitting. With no discount for perishable products to enhance inventory depletion rate for profit maximization is an area of interesting research. This paper introduces the concept of entropy cost to account for hidden cost such as the additional managerial cost that is needed to control the improvement of the process with insignificant difference in traditional model. This paper examines the idea by extending the analysis of other related papers by introducing entropy cost and allowing no discount in selling price to provide a firm with its optimum replenishment schedule, replenishment order quantity and entropy cost, simultaneously in order to achieve its maximum profit.

These models can be considered in a situation in which the entropy cost can be adjusted and the number of price changes can be controlled. Extension of the proposed model to unequal time price changes and other applications will be a focus of the future work.

\section{CONCLUSION}

This paper presented an entropic order quantity model for perishable items with two component demand in which the criterion is to optimise the expected total finite horizon payoff. Finally, in numerical experiments the solution from the entropic model evaluated and compared to the solutions of other different traditional EOQ and EnOQ policies respectively.

However, a few performance differences among a set of different inventory policies in the existing literature. Although there are minor variations that do not appear significant in practical terms, at least when solving the single level, incapacitated version of the lot sizing problem. The results of this study give managerial insights to decision maker developing an optimal replenishment decision for deteriorating product. Compensation mechanism should also be included to induce collaboration between retailer and dealer in a meaningful supply chain.

In general, for normal parameter values the relative payoff differences seem to be fairly small. The optimal solution of the suggested entropic order quantity model has a higher total payoff as compared with optimal solution for the traditional EOQ policy. Conventional wisdom suggests that workflow collaboration in an EnOQ model in a varying deteriorating product in market place are promising mechanism and achieving a cost effective replenishment policy.

The approach proposed in the paper based on EnOQ model seems to be a pragmatic way to approximate the optimum payoff of the unknown group of parameters in inventory management problems. The assumptions underlying the approach are not strong and the information obtained seems worthwhile. Investigating optimal policies when demand are generated by other process and designing models that allow for several orders outstanding at a time would also be challenging tasks for further developments. Its use may restrict the model's applicability in the real world. Future direction may be aimed at considering more general 
deterioration rate or demand rate. Uses of other demand side revenue boosting variables such as promotional efforts are potential areas of future research. The proposed paper reveals itself as a pragmatic alternative to other approaches based on two component demand function with very sound theoretical underpinnings but with few possibilities of actually being put into practice. The results indicate that this can become a good model and can be replicated by researchers in neighbourhood of its possible extensions. As regards future research, one other line of development would be to allow shortage and partial backlogging in the discounted model

\section{REFERENCES}

Chung, Y. D., Tsu, P. H. and Liang, Y. (2007). Determining optimal selling price and lot size with a varying rate of deterioration and exponential partial backlogging. European Journal of Operational Research 181, pp. 668-678.

Deb, K., (2000). Optimization for Engineering Design, Prentice-Hall, New Delhi, India.

Goswami, A. and Choudhury, K. S. (1995). An EOQ model for deteriorating items with linear time dependent demand rate and shortages under inflation and time discounting. Journal of Operational Research Society 46(6), pp. 771.

Goyal, S. K.and Giri, B. C. (2001). Recent trends in modelling of deteriorating inventory. European Journal of Operational Research 134, pp. 1-16.

Jaber, M. Y., Bonney, M., Rosen, M. A., and Moualek, I. (2009). Entropic order quantity (EnOQ) model for deteriorating items. Applied mathematical modelling 33(1), pp. 564-578.
Pal, S., Goswami, K. and Chaudhuri, K. S. (1993). A deterministic inventory model for deteriorating items with stock dependent demand rate. Journal of Production Economics 32, pp. 291-299.

Panda, S., Saha, S., and Basu, M. (2009). An EOQ model for perishable products with discounted selling price and stock dependent demand. Central European Journal of Operational Research 17, pp. 31-53.

Pattnaik, M., (2010). An Entropic Order Quantity Model (EnOQ) under Instant Deterioration of Perishable Items with Price Discounts. International Mathematical Forum 5, pp. 2581-2590.

Pattnaik, M. (2011). An Entropy Order Quantity (EnOQ) Model with Post Deterioration Cash Discounts. International Journal of Contemporary Mathematical Sciences 6(19), pp. 931-939.

Raafat, E. (1991). Survey of Literature on Continuously Deteriorating Inventory Model. Journal of Operational Research Society 42, pp. 2737.

Silver, E. A., and Peterson, R. (1985), Decision system for inventory management and production planning, $2^{\text {nd }}$ edition, Willey, New York.

Skouri, K., Konstantaras, I., Papachristos, S., and Ganas, I. (2007). Inventory models with ramp type demand rate, partial backlogging and weibull deterioration rate. European Journal of Operational Research.

Tripathy, P. K., and Pattnaik, M. (2008). An Entropic Order Quantity Model with Fuzzy Holding Cost and Fuzzy Disposal Cost for Perishable Items under Two Component Demand and Discounted Selling Price. Pakistan Journal of Statistics and Operations Research 4(2), pp. 93110.

Urban, T. L. (2005). Inventory model with inventory level dependent demand a comprehensive review and unifying theory. European Journal of Operational Research 162, pp. 792-804.

Wee, H. M., and Law, S. T. (2001). Replenishment and pricing policy for deteriorating items taking into account the time value of money. International Journal of Production Economics 71, pp. 213-220.

Weatherford, L. R., and Bodily, S. E. (1992). A Taxonomy and Research Overview of Perishable Asset Revenue Management: Yield Management, Overbooking, and Pricing. Operations Research 40, pp. 831-844.

Dr. Monalisha Pattnaik is lecturer of Department of Business Administration at Utkal University, Odisha, India. She received her Ph. D. in Operations Research (Statistics) from Utkal University. Her research interests cover areas in Operations Research, Production Planning, Inventory Control, Project Management, Operations Management, General Management, Fuzzy Sets, Applied Statistics, Applied Mathematics, Decision Sciences and Optimization. Dr. Monalisha is an editor of some international journals e.g. Journal of Business Management and Economics, General Mathematics Notes, The Journal of Mathematics and Computer Science and Thailand Statistician. She has published several articles in numerous international journals e.g. Applied Mathematical Sciences, Pakistan Journal of Statistics and Operations Research, International Mathematical Forum, The Open Operational Research Journal, International Journal of Scientific and Statistical Computing, International Journal of Management Science and Engineering Management, International Journal of Contemporary Mathematical Sciences, Thailand Statistician, The Journal of Mathematics and Computer Science. 